\title{
Aspergillus surveillance project at an urban hospital
}

Salvatore Cali, Dr. Peter Scheff, Dr. Lorraine Conroy, Luke Curtis, Kirk Baker, Chia-Hao Ou, Felice Norlock Environmental \& Occupational Health Sciences Division

School of Public Health, University of Illinois at Chicago, U.S.A.

\section{Abstract}

Aspergillus organisms are common in most ambient environments. Aspergillus organisms do not normally present a danger to healthy people, but have the potential to cause invasive disease and death in immune-compromised persons. Our department conducted a one-year surveillance study to evaluate the exposure potential at an urban, public hospital with four treatment areas for immunecompromised patients. Elements of the study included air sampling for Aspergillus organisms and other bio-aerosols, characterization of the ventilation and HVAC systems, characterization of dust collected during routine duct cleaning activities for the presence of an Aspergillus fumigatus protein, and considerations of duct cleaning and renovation/remodeling activities. The air sampling was conducted over a full year at six-day intervals.

This study found that airborne Aspergillus, including the species implicated in infected hospital patients (A. fumigatus), was present in the air in all areas studied. The relationship between inside and outside concentrations of Aspergillus was very weak. A model of the penetration of organisms into the hospital showed that infiltration of outside air was not the primary source for the airborne Aspergillus levels found inside. Average airborne Aspergillus concentrations inside the hospital were dominated by several high concentration events. Although there appeared to be several sources inside, the dissemination of viable organisms occurred in specific time periods that may be directly related to operation of the air handling systems and outdoor weather. Duct cleaning and renovation/construction activities intermittently generated elevated concentrations of airborne bioaerosols. 


\section{Introduction}

Invasive aspergillosis is a life-threatening disease that has become increasingly common over the last two decades. One report shows a 14-fold rise of invasive aspergillosis over 12 years. Denning quoting Groll [1]. This increase is likely associated with the increasing use of advanced medical procedures that involve therapy-induced granulocytopenia, which results in a severe weakening of the immune system. Aspergillosis incidence is generally on the order of $1-4 \%$ in most patient populations with disease-induced granulocytopenia, with the exception of acute leukemia (5-24\% incidence). In patient populations with therapy-induced granulocytopenia, the incidence can be much higher, on the order of $1-26 \%$, depending on the procedure. Much higher incidence rates, up to $95 \%$, are quoted in older literature, although these rates have apparently been reduced more recently. The reduction in incidence may be due to increased awareness and controls as well as oral, systemic, and intra-nasal antifungal drug prophylaxis. In 1997, the two licensed drugs for use against Aspergillus (amphotericin B and itraconazole) accounted for $\$ 370$ million, $30 \%$ of sales of antifungal drugs.

When aspergillosis does occur, the mortality rate is $50-100 \%$, even with therapy. [1]. Therefore, prevention takes on even more importance with invasive aspergillosis than most other infectious diseases. Allergic broncho-pulmonary aspergillosis (ABPA) is currently being diagnosed with greater frequency as a complication in patients with asthma and cystic fibrosis, in whom the incidence may be as high as $10 \%$. Aspergillus infections of surgical wounds are also cited in literature. It is currently believed that Aspergillus fumigatus is involved in up to $80 \%$ of Aspergillus-related diseases, making this species the most clinically important of the genus. Kurup, et al [2]. Aspergillus flavus infections are also commonly mentioned in literature, along with invasive infections from other species or combinations of species, though with less frequency.

In response to concern for potential Aspergillus exposure, our department conducted a one-year study at the study hospital. Elements of the study included:

- Air sampling for Aspergillus organisms and other bio-aerosols;

- Characterization of the ventilation and HVAC systems;

- In-depth evaluation of the dedicated air handling system for the Bone Marrow Transplant Unit;

- Characterization of dust collected during routine duct cleaning activities for the presence of an Aspergillus fumigatus protein;

- Considerations of renovation/remodeling activities.

The work proposal was accepted by the hospital in August of 1998, and air sampling was conducted from September 9, 1998 through September 16, 1999. Some modifications to the original study design were made as results and events unfolded during the study, including a concern over duct cleaning maintenance operations that were intensified at about the same time that the study period began.

The objectives of the study were to:

- Establish the absence or presence and concentration of Aspergillus in air in the four treatment areas housing immune-compromised patients; 
- Establish airborne exposure patterns by season and control for these patterns;

- Use the data to identify potential sources of airborne Aspergillus;

- Evaluate maintenance duct cleaning as a possible source of airborne Aspergillus;

- Evaluate construction/renovation activities as a possible source and evaluate containment structure effectiveness for control of airborne Aspergillus.

At this time, thresholds or limits for acceptable Aspergillus concentrations in air do not exist for exposures in environmental, occupational, or health care settings. The dose-response relationship between exposure and health effects of most bio-aerosols, including Aspergillus, is not well established.

\section{Methods}

\subsection{Air Sampling}

For sampling media, we used a standard malt extract media containing 20 grams of malt extract, 20 grams of glucose, 20 grams of agar, and I gram of peptone per liter of distilled water. Potassium phosphate was added to adjust the $\mathrm{pH}$ to 5.0-5.5. Media was autoclaved at $15 \mathrm{psi}$ and $121^{\circ} \mathrm{C}$ for 20 minutes.

Air sampling was performed by collecting paired sets of samples. Two different volumes of air in each pair were used for reasons involving both quality control and to help obtain the optimal sampling volume for colony counting purposes. The air sampling was usually performed every six days by pulling at least 50 and 100 liters of air per sample pair through Anderson N6 sampling devices at a rate of 41.1 liters per minute. This volume was doubled twice during the winter to optimize plate colonization, and reduced in the spring through the end of the study.

The sample volume was set to collect the maximum number of colonies per growth plate without over-colonizing the plates with organisms, which could result in undercounting. Over-colonization did not seem to occur in this study, so the concentrations of each pair were averaged in the data used for this report. Our results indicate that our strategy was appropriate. All of the results are reported in colony forming units per cubic meter $\left(\mathrm{cfu} / \mathrm{m}^{3}\right)$ of air. After sample collection, the plates were incubated at ambient indoor temperature (approximately $22^{\circ} \mathrm{C}$ ) for 4 to 6 days. The growth colonies were then identified according to genus and species, and counted. High colony counts were adjusted according to the Anderson Correction Listing Table 1, specific to the sampler and number of air entry holes.

The Anderson N6 sampler was chosen for this study because it is widely used and the performance is well-characterized for collection of micron-sized particles such as Aspergillus spores and viable matter. ACGIH [3]. The samplers were autoclaved before each use.

Quality control was performed by making two extra sample collection plates with growth media from the same batch as the sampling growth media each sampling day. These plates were handled, transported, and incubated in the same manner as the air sample collection plates.

Our strategy was to conduct sampling in several rotations relevant to maintenance duct cleaning, construction/renovation, outside, and in four target areas of the hospital 
that generally house immune-compromised patients. Samples were collected once every six days during the sampling period to control for possible differences relative to days of the week. Each sampling day typically included: One pair of samples in patient rooms in each of two of the four units (4 samples); one pair of samples outside patient rooms (usually nurse's stations) in two of the four units (4 samples); one pair of samples inside rooms or containment where a maintenance activity (either construction/renovation or duct cleaning) was being conducted ( 2 samples); one pair of samples outside rooms or containment where a maintenance activity (either construction/renovation or duct cleaning) was being conducted ( 2 samples); one pair of outside samples (usually on the $9^{\text {th }}$ floor rooftop) every sampling day ( 2 samples). The rotation allowed sampling in every patient area every 12 days, sampling of a maintenance activity (either renovation/remodeling or duct cleaning) every 6 days, and outside sampling every 6 days. This regimen totaled 14 samples per sampling day plus two control plates.

\subsection{Ventilation Characterization}

The ventilation system was characterized through several interviews with hospital physical plant staff and by performing intermittent ventilation measurements in a total of 30 patient rooms over 22 dates interspersed throughout the sampling period. The ventilation measurements were made with an Alnor Balometer and/or a TSI Velocicalc thermo-anemometer air velocity measurement device at supply and exhaust grills.

The Bone Marrow Transplant Unit, which has a dedicated HEPA filtered system, was also characterized in depth. In addition to the ventilation measurements, a Dwyer Micro-manometer pressure differential measurement device was used to measure pressure differential at doorways between patient rooms and the unit, and between the unit and the adjacent hospital areas. The HEPA filters for this unit were tested for integrity and efficiency with a TSI Model 8028 Portacount. The Portacount operates by counting ambient dust particles. Probes were placed on both sides of the HEPA filters and the particle count before and after the filters was compared.

\subsection{Dust Sampling}

Dust was collected from portable HEPA vacuum bags used by hospital maintenance staff to clean the duct covers in patient rooms and other areas. We had attempted to collect dust from patient room floors by using a portable vacuum, but an insufficient amount of dust was collected to utilize this method. Approximately 100 milligrams of dust was taken out of each bag and analyzed using the Sandwich ELISA (Enzyme Linked Immunosorbent Assay) method of Arruda et al [4]. This method measures the asp $\mathrm{fl}$ protein from the mycelia of Aspergillus fumigatus. This protein is only found on the mycelia of this species and is not found on the infectious spores. Airborne mycelia can also be infective, but less so than the spores. This test was useful to detect the presence of Aspergillus fumigatus, but was not useful for quantification or comparison of exposure in different areas. 


\section{Results \& Discussion}

\subsection{Summary Data}

There were a total of 64 days in which sampling was performed. Of these, three regular sample rotation results were unusable because the sampling media or sampler configuration failed, or the samples were inadvertently lost or destroyed. One sampling day consisted of six samples instead of the usual 14 , because it was confined to one target area and was performed outside of the six-day rotation in order to confirm high Aspergillus concentrations not previously seen in the study.

Table 1 provides preliminary indications relevant to presence and possible sources of Aspergillus by presenting basic statistics of the results by area/activity category.

Table 1: Air Sampling Data Summary by Hospital Area

\begin{tabular}{|c|c|c|c|c|c|c|}
\hline $\begin{array}{l}\text { UNIT \#/ } \\
\text { ACTI- } \\
\text { VITY: }\end{array}$ & $\begin{array}{c}\text { AREA } \\
\text { (In/Out } \\
\text { Patient } \\
\text { rooms or } \\
\text { contain- } \\
\text { ment): } \\
\end{array}$ & $\begin{array}{c}\# \\
\text { Sam- } \\
\text { ples }\end{array}$ & $\begin{array}{c}\text { AVERAGE } \\
\text { Total } \\
\text { Recoverable } \\
\text { Org's } \\
\text { (cfu/m3): }\end{array}$ & $\begin{array}{l}\text { AVERAGE } \\
\text { Total \# of } \\
\text { Recoverable } \\
\text { Aspergillus } \\
\text { (cfu/m3): }\end{array}$ & $\begin{array}{c}\text { \% of } \\
\text { samples } \\
\text { Positive for } \\
\text { Aspergillus } \\
\text { (\%) }\end{array}$ & $\begin{array}{c}\text { ASPER- } \\
\text { GILLUS } \\
\text { As \% of } \\
\text { Total } \\
\text { Organisms } \\
(\%) \\
\end{array}$ \\
\hline \multirow{2}{*}{$\begin{array}{c}\text { Cardiac } \\
\text { Intensive } \\
\text { Care } \\
\end{array}$} & In & 58 & 54.9 & 16.8 & 43 & 30.7 \\
\hline & Out & 57 & 34.6 & 8.4 & 35 & 24.2 \\
\hline \multirow{2}{*}{$\begin{array}{c}\text { ADS } \\
\text { Treat- } \\
\text { ment } \\
\end{array}$} & In & 58 & 41.7 & 7.6 & 41 & 18.1 \\
\hline & Out & 58 & 37.1 & 10.0 & 38 & 27.0 \\
\hline \multirow{2}{*}{$\begin{array}{c}\text { Organ } \\
\text { Trans- } \\
\text { plant } \\
\end{array}$} & In & 71 & 83.5 & 30.6 & 44 & 36.6 \\
\hline & Out & 62 & 44.8 & 12.7 & 34 & 28.4 \\
\hline \multirow{2}{*}{\begin{tabular}{|c|} 
Bone \\
Marrow \\
Transpl'nt \\
\end{tabular}} & In & 62 & 41.0 & 7.3 & 31 & 17.9 \\
\hline & Out & 62 & 40.7 & 8.4 & 19 & 20.5 \\
\hline \multirow{2}{*}{\begin{tabular}{|c|} 
Duct \\
Cleaning
\end{tabular}} & In & 23 & 192.8 & 22.6 & 35 & 11.7 \\
\hline & Out & 21 & 70.4 & 17.5 & 38 & 24.8 \\
\hline \multirow[t]{4}{*}{$\begin{array}{l}\text { Reno- } \\
\text { vation }\end{array}$} & $\begin{array}{l}\text { In, not } \\
\text { active }\end{array}$ & 76 & 38.1 & 6.4 & 28 & 16.7 \\
\hline & $\begin{array}{l}\text { Out, not } \\
\text { active }\end{array}$ & 68 & 37.5 & 4.2 & 32 & 11.1 \\
\hline & In, active & 22 & 100.6 & 13.2 & 55 & 13.2 \\
\hline & Out, active & 22 & 57.4 & 14.7 & 41 & 25.6 \\
\hline \multicolumn{2}{|c|}{ Rooftop/Exterior } & 122 & 257.8 & 6.8 & 43 & 2.6 \\
\hline
\end{tabular}




\subsubsection{Patient Areas:}

For results inside patient areas of the hospital:

1. Aspergillus is present in air in all of the target areas of the hospital;

2. Exterior samples had a comparable percentage of plates with some Aspergillus colonization ( $43 \%$ compared to $19-44 \%$ ), but a lower average concentration of Aspergillus $\left(6.8 \mathrm{cfu} / \mathrm{m}^{3}\right)$ than all of the patient areas $\left(7.3-30.6 \mathrm{cfu} / \mathrm{m}^{3}\right)$;

3. Among the exterior samples, Aspergillus made up a smaller percentage $(2.6 \%)$ of overall organisms collected than among samples in patient areas (17.9 - 36.6);

4. Exterior samples had a much higher average concentration of total recoverable organisms $\left(257.8 \mathrm{cfu} / \mathrm{m}^{3}\right)$ than patient areas $\left(34.6-83.5 \mathrm{cfu} / \mathrm{m}^{3}\right)$;

5. Among the patient areas, the concentrations and percentage of positive samples were lowest throughout the Bone Marrow Transplant Unit.

6. Of the four patient areas, two had higher concentrations inside patient rooms (Cardiac Intensive Care and Organ Transplant) than outside patient rooms.

The fact that average Aspergillus concentrations were higher inside all patient areas compared to concentrations outside the hospital, while average total recoverable organism concentrations were significantly lower inside, argues against infiltration of Aspergillus from outside as the primary source. It is likely that there is a source or sources of airborne Aspergillus dissemination and/or amplification within the hospital. More detailed analysis of data provided below reinforces this assertion.

\subsubsection{Duct Cleaning Activities:}

Duct cleaning at the hospital was routine maintenance cleaning instituted in response to state accreditation inspections. Lint from bed coverings collects, along with dust, very quickly on exhaust ducts and screens on induction units, which re-circulate air within patient rooms. The duct cleaning operations included removing duct supply and exhaust covers, cleaning the covers with rags, and then HEPA vacuuming inside the duct to the areas within arms reach with normal hose attachments. Window induction units were cleaned by first removing the cover on the face of the unit, then vacuuming the screen and accessible areas inside.

Results from duct cleaning collected early in this study generated considerable concern and were brought to the attention of hospital infection control. A policy change mandated that maintenance personnel perform duct cleaning in vacant patient rooms and with the door closed only. Unfortunately, air sampling of duct cleaning was not consistently performed throughout the duration of the study, and subsequent results do not provide us with much useful information regarding this activity. However, the details about Aspergillus species discussed below are of interest in regard to this activity. Further areas of inquiry include study of each phase of the cleaning process as well as residence time of the Aspergillus spores in the air after cleaning is completed.

\subsubsection{Renovation/Remodeling Activities:}

It has been established in many previous studies that construction, renovation/remodeling, and other activities that disturb dust can cause elevated airborne concentrations of Aspergillus. Summary concentrations of Aspergillus shown in Table 1 do not reinforce this, although the percentage of samples counted as positive for 
Aspergillus is higher inside containment during active renovation (55\%) than in patient areas of the hospital (19-44\%). The concentration of total recoverable organisms was also higher inside containment during active renovation $\left(100.6 \mathrm{cfu} / \mathrm{m}^{3}\right)$ than in patient areas $\left(34.6-83.5 \mathrm{cfu} / \mathrm{m}^{3}\right)$. Activities sampled during this study generally consisted of tasks related to painting, drywall, and electrical work, as opposed to demolition type activities. Two samples collected on the same day, adjacent to an area where wood was being cut with a power saw, account for more than half of the total Aspergillus organisms $\left(170 \mathrm{cfu} / \mathrm{m}^{3}\right)$ of the total $\left(291 \mathrm{cfu} / \mathrm{m}^{3}\right)$ in the category.

It is interesting to note that in the other three categories of renovation, results showed generally lower or equivalent concentrations and positive result percentages than results in patient treatment areas. Much of the sampling in these categories was done in a new admission and emergency area being constructed on the ground floor of the hospital. Other samples were collected in rooms where the ventilation system was covered and/or inactive. This finding begs a consideration of the ventilation system as a source or amplifier of Aspergillus in the patient areas. The hospital ventilation system is described briefly below along with the air sampling findings in patient areas.

\subsubsection{Aspergillus Species Fingerprint}

Figure 1 below illustrates a breakdown of Aspergillus species as a percent of total Aspergillus collected.

Figure 1: Aspergillus Species Fingerprint

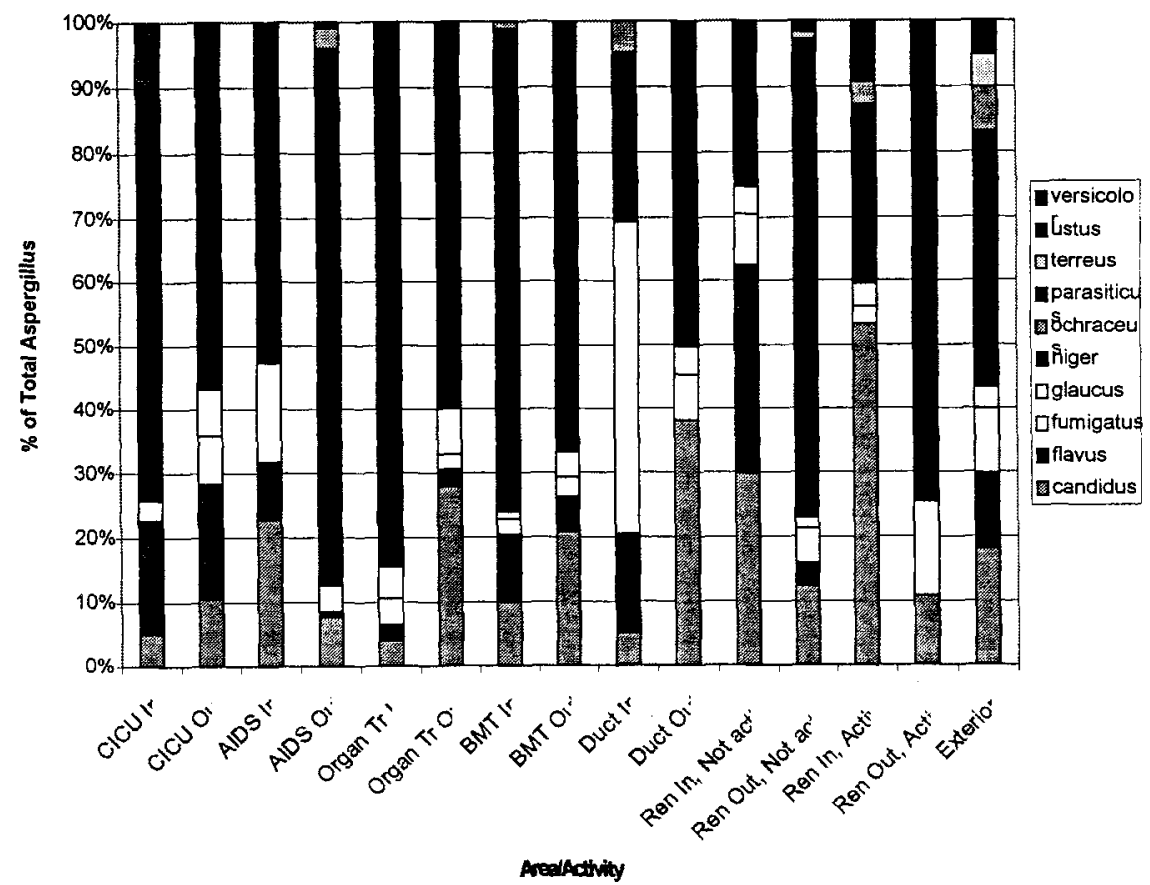


The data for this illustration was calculated by dividing the sum of the study period concentration of each Aspergillus species by the sum of the total study period Aspergillus concentration for all species in each activity/area category. A clear pattern across areas or activities is not readily apparent from this information, which indicates that there are probably multiple sources of Aspergillus growth in the hospital. Another interesting observation from this breakdown is that the share of $A$. fumigatus is quite high (48\%) from duct cleaning activities. This is much higher than the share in any other category, the next highest being $15.5 \%$ in patient rooms in the AIDS Treatment Unit. This finding is also consistent with the ELISA tests performed on vacuum bags from the duct cleaning operations. The ELISA tests found detectable quantities of the target $A$. fumigatus protein in $65 \%$ of the samples. The concentrations of the protein were low, on the order of 0.02 to $1.94 \mathrm{ppm}$, but as mentioned earlier, the method only detects a fraction of the organism.

\subsubsection{High Aspergillus Concentration Incidents}

The species fingerprint and the category concentrations were generally greatly influenced by a relatively low number of high concentration samples, thereby causing a bias in statistical analysis of results. In all area and activity categories, the three highest concentration samples accounted for 35 to $78 \%$ of the total Aspergillus count, except outdoors where the three highest samples only made up $18 \%$ of the total. In most categories, two of the three single samples were collected in the same sample pair.

The highest concentrations collected in the hospital are also much higher than the highest concentrations outside. This observation again argues against infiltration. It also call for a consideration of particular factors that cause dissemination of the viable components of Aspergillus.

There were two major incidents when high concentrations of airborne Aspergillus were collected in December, 1998 and April. 1999, and some relatively smaller incidents in June and July of 1999. These incidents were characterized by high concentrations in samples collected in all four treatment areas, especially inside patient rooms. Each incident continued over several sampling periods, indicating that the duration of the incidents was 12 to 30 days. Although this creates an argument for a systemic dissemination of viable Aspergillus, differences in species patterns argue in favor of multiple sources of Aspergillus.

\subsubsection{Possible Sources of Aspergillus Growth in the Hospital}

Several sources of Aspergillus growth were identified through observation and interviews with hospital maintenance personnel:

1. A plumbing leak above the Organ Transplant Unit caused visible water damage in a room in the Unit and a room directly below in the Cardiac Intensive Care Unit. These two units had higher average Aspergillus concentrations in patient rooms than outside the patient rooms. The leak was repaired after December.

2. A roof leak above the Bone Marrow Transplant Unit caused visible ceiling tile damage outside the unit entrance doors. The leak was apparently caused by the installation of the dedicated air handling system for the unit. The roof membrane was cut for the installation. Water leaked in at the seam of the air handler and 
flowed across and through a concrete roof layer. This leak was repaired a few months after this study began.

3. There were numerous reports of a chronic window leak problem throughout the entire sampling period. The seals around the window assemblies had failed over a long period of time. Precipitation running down the outside walls of the building would be drawn into the window areas by a capillary effect. The leaks and condensation could have provided a constant growth area for fungal organisms.

4. Seasonal high concentration incidents indicate that dissemination may be related to ventilation system operation. All four patient units had different ventilation configurations. All units are humidified in winter by steam sprayed into the systems downstream from the supply fans, and dehumidified by the respective cooling coils in each system.

Findings in the Bone Marrow Transplant Unit were particularly perplexing. The unit is ventilated by a dedicated, HEPA filtered system that is designed to keep the rooms and unit under strong positive pressure relative to other areas. Air flow is on the order of $16-30 \mathrm{ACH}$ (Air Changes per Hour). This area is heated by air passing over steam coils in the ceiling. Our evaluation of the HEPA filters, performed in June, 1999, indicated that the filters were properly installed and operating according to the rated efficiency for such filters.

All of the units are designed to supply positive pressure in the patient rooms relative to the corridors. Our ventilation measurements indicated that this was generally true. With four different ventilation systems throughout the hospital, there did not appear to be a common source of growth and dissemination, except humidification. In December 1998 , outside daily average temperatures dropped from the mid- $50^{\circ} \mathrm{F}\left(12^{\circ} \mathrm{C}\right)$ range to the mid- $30^{\circ} \mathrm{F}\left(2^{\circ} \mathrm{C}\right)$ range immediately before the elevated Aspergillus concentration incident. The April incident occurred shortly after average temperatures jumped from the mid- $30^{\circ} \mathrm{F}\left(2^{\circ} \mathrm{C}\right)$ range in mid-March to the mid $-60^{\circ} \mathrm{F}\left(18^{\circ} \mathrm{C}\right)$ range in early April. The less extreme incidents in July occurred during very hot and humid temperatures.

It is known that fungi spores are forcibly ejected from asci in response to changing relative humidity, and dry air as well as air movement contribute to the dissemination of the spores. If there is fungal growth present within the building, it is possible that the initial seasonal operation of either the heating or cooling systems contributed to the dispersion of spores. 


\section{Conclusions}

1. Aspergillus, including the species implicated in infected hospital patients (A. fumigatus), was found in all of the four target treatment areas and other non-target areas inside of the hospital, including the Bone Marrow Transplant Unit supplied by a dedicated, positively pressured, HEPA filtered air handling unit.

2. Infiltration is not the primary mechanism for the airborne Aspergillus levels found inside the hospital.

3. Average airborne Aspergillus concentrations in patient areas of the hospital are dominated by several high incidence and concentration events. Species contributions varied during these events and in different patient areas of the hospital, indicating multiple sources of Aspergillus. However, dissemination appeared to occur in specific time periods that may be related to outdoor weather and operation of the air handling systems.

4. Renovation/construction activity results were generally comparable or lower than other areas. Most renovation activities sampled involved activities that did not generate high concentrations of airborne Aspergillus, although occasional relatively high samples were collected.

5. Duct cleaning operations can generate high concentrations of $A$. fumigatus.

\section{References}

1) Denning, quoting Groll, et al., J Infection 1996; 33: 23-32, and presentation summary in Report on a European Science Foundation Workshop on Invasive Aspergillosis, October, 1998

2) Kurup, Viswanath, $\mathrm{PhD}$, Banani Banerjee, $\mathrm{PhD}$, Paul Greenberger, $\mathrm{MD}$, Jordan Fink, MD, Allergic Bronchopulmonary Aspergillosis: Challenges in Diagnosis, 1999, from Medscape Respiratory Care Home Page. http://ww.medscape.com (accessed January, 2000).

3) American Conference of Governmental and Industrial Hygiene (ACGIH), Bioaerosols: Assessment and Control, ACGIH Publications, Cincinnati, Ohio, 1999; Table 11.1, pgs 11-4 thru 11-6.

4) Arruda, L.K., Platt-Mills, T. A. E., Longbottom, J.L., El-Dahr, J.M., Aspergillus fumigatus: Identification of the 16,18 , and $45 \mathrm{kD}$ antigens recognized by human IgG and IgE antibodies and murine monoclonal antibodies. Journal of Allergy and Clinical Immunology, 1992; 89: pgs 1166-1176. 